\title{
Video Article \\ Nerve Stimulator-guided Injection of Autologous Stem Cells Near the Equine Left Recurrent Laryngeal Nerve
}

\author{
Charlotte Sandersen ${ }^{1}$, Justine Ceusters ${ }^{1}$, Alexia Fourez ${ }^{1}$, Irene Tosi ${ }^{1}$, Helene Graide ${ }^{1}$, Jean-Philippe Lejeune ${ }^{1,2}$, Didier Serteyn ${ }^{1,2}$ \\ ${ }^{1}$ Department of Clinical Sciences, Faculty of Veterinary Medicine, University of Liege \\ ${ }^{2}$ Mont-le-Soie Equine Research Centre
}

Correspondence to: Charlotte Sandersen at charlotte.sandersen@uliege.be

URL: https://www.jove.com/video/58023

DOI: doi: $10.3791 / 58023$

Keywords: Medicine, Issue 139, Horse, recurrent laryngeal neuropathy, nerve stimulation, stem cells, endoscopy, muscle microbiopsy, peripheral neuropathy

Date Published: 9/26/2018

Citation: Sandersen, C., Ceusters, J., Fourez, A., Tosi, I., Graide, H., Lejeune, J.P., Serteyn, D. Nerve Stimulator-guided Injection of Autologous Stem Cells Near the Equine Left Recurrent Laryngeal Nerve. J. Vis. Exp. (139), e58023, doi:10.3791/58023 (2018).

\section{Abstract}

Recurrent laryngeal neuropathy (RLN) commonly affects horses and is characterized by abnormal respiratory sounds and exercise intolerance. The recurrent laryngeal nerve shows lesions of demyelination. The benefit of applying stem cells to demyelinated nerves has been demonstrated in various animal models. The aim of the study was to test the feasibility and safety of a peri-neuronal injection of autologous muscle-derived mesenchymal stem cells to the left recurrent laryngeal nerve in healthy horses by using an electrical nerve stimulator.

Muscle-derived stems cell are obtained from five healthy Standardbred horses by sampling $20 \mathrm{mg}$ of muscle tissue with a semi-automatic $14 \mathrm{G}$ biopsy needle from the triceps muscle. Movements of the larynx are monitored via upper-airway video endoscopy. The left recurrent laryngeal nerve is approached with an insulated nerve block needle. Nerve stimulation is applied, starting at $2 \mathrm{~mA}$, and the successful abduction of the left arytenoid is monitored. The stimulation intensity is reduced progressively. When a loss of the motor response is observed at $0.5 \mathrm{~mA}, 10^{7}$ autologous muscle-derived stem cells are injected. Two examiners, who are blinded to the time point, score the laryngeal function of the horses prior to the treatment and at day 1 , day 7 , and day 28 after the injection of the cells. In a sixth horse, $1 \mathrm{~mL}$ of $2 \%$ lidocaine is injected to further confirm the correct positioning of the needle. This leads to a temporary paralysis of the left arytenoid cartilage.

This study proves that the recurrent laryngeal nerve can be approached with the help of an electrical nerve stimulator and that the electrical stimulation of the nerve is well tolerated by the horses. No modification of the laryngeal function was observed in any of the horses after the injection of the stem cells. Further studies should be conducted to describe the effects of a peri-neuronal injection of autologous muscle-derived mesenchymal stem cells to horses suffering from RLN.

\section{Video Link}

The video component of this article can be found at https://www.jove.com/video/58023/

\section{Introduction}

$\mathrm{RLN}$ is a common pathology of the upper airway in horses characterized by varying degrees of arytenoid paralysis. The left side of the larynx is most commonly affected. The prevalence of the disease can reach up to $35 \%$ in certain horse populations. Although several hypotheses tried to explain the etiology and pathogenesis of this disease, the exact cause of RLN remains uncertain. The pathology is described as a distal axonopathy of the recurrent laryngeal nerve with lesions of demyelination but also some degree of remyelination. This axonopathy leads to the denervation of intrinsic laryngeal muscles and concomitant atrophy ${ }^{1,2}$. This pathology is often slowly progressive and may lead to a total loss of the arytenoid abduction of the affected side ${ }^{3}$.

Affected horses emit abnormal respiratory sounds during exercise and, sometimes, show exercise intolerance in more severe cases. The definitive diagnosis is made by the endoscopic examination on a non-sedated standing horse where a partial or total loss of laryngeal abduction is observed ${ }^{1,2,4}$. Currently, the most common treatment is laryngoplasty (also known as "tie-back"), which is sometimes associated with a ventriculo-cordectomy. Although the overall success rate of these surgeries is considered as good to excellent ${ }^{5}$, post-operative complications are very common. The most common complication is a gradual loss of abduction. Barnett et al. ${ }^{6}$ reported a loss of at least one grade of abduction within the first six weeks following the surgery in at least $76 \%$ of horses. Other complications, such as prosthesis failure, coughing, and airway contamination, are also reported ${ }^{5}$.

Mesenchymal stem cells (MSCs) have been a part of equine medicine in research and practice for more than a decade, although proven studies on their efficiency are still scarce. The two most commonly exploited sources of adult mesenchymal stem cells in horses are bone marrow and adipose tissue ${ }^{7}$. Both sampling techniques are relatively invasive and do not always lead to a sufficient number of cells. Recently, Ceusters et al. ${ }^{7}$ described the culture of stem cells derived from striated muscle tissue, which is obtained by a less invasive microbiopsy technique. 
MSCs are capable of self-renewal, self-generation, multipotency, and differentiation ${ }^{7,8}$. Their ability to differentiate into all mesoderm lineages of fat, bone, muscle, and cartilage is now well established ${ }^{9}$. However, under specific environmental conditions, they can differentiate into nonmesenchymal lineages such as neurons, astrocytes, and myelinating cells of the peripheral nervous system and the spinal cord ${ }^{9,10}$. MSCs have already been used in several neuropathy models ${ }^{10,11}$. Their ability to migrate into areas of degenerated nervous tissue and to regenerate neural cells has been demonstrated after a systemic and local administration ${ }^{11}$. Moreover, Schwann-like cells derived from MSCs can recruit macrophages to remove cellular debris and secrete neurotrophic factors promoting axonal growth and remyelination ${ }^{9}$.

The aim of this study is to describe the technique of a nerve stimulator-guided injection of muscle-derived autologous stem cells near the left recurrent laryngeal nerve in healthy horses. Typically, a nerve stimulator connected to an injection needle is used for the electro-localization of peripheral nerves in order to apply local anesthetics to that area ${ }^{12}$. A weak direct current impulse is supplied in proximity to the nerve to induce a motor response. The ability to produce this motor response depends on several parameters, such as the conductive area of the needle, any impedance of the tissue, the current applied, the pulse duration, and the distance from the needle to the nerve. Nerve stimulator needles are designed to have a very restrictive conductive area at the tip of the needle, while the rest of the needle is insulated. This design helps to precisely localize the nerve. Modern nerve stimulators adapt to varying tissue impedances and deliver the constant amperage set on the machine. Furthermore, most machines use a pulse duration of $0.1 \mathrm{~s}$, so that the determinative parameters are the current applied and the distance to the needle. The relationship between the needle-to-nerve distance and the current necessary to produce a motor response is described by Coulomb's law: $E=k Q / r$; where $E$ is the required stimulation charge, $k$ is Coulomb's constant, $Q$ is the minimal required stimulation charge, and $r$ is the distance between the two electrodes. In the electro-localization of nerves, the distance between the two electrodes is considered to be the needle-to-nerve distance ${ }^{12}$. Electrical charge dissipates following the rule of the inverse square of the needle-to-nerve distance $^{13}$. Clinical practice has shown that the motor nerve stimulation at $0.5 \mathrm{~mA}$ is highly correlated to the successful nerve block and that a loss of motor signal at lower currents will prevent the user from administering accidental intraneuronal injections. The aim of this study is to test the feasibility and safety of this technique in a limited number of horses. If the feasibility and safety of this technique are confirmed, it can be easily transferred to affected horses. Further, equine RLN can serve as a model for peripheral degenerative neuropathy.

\section{Protocol}

The commission for the ethical use of animals of the University of Liege approved the study protocol.

\section{Muscle Microbiopsy}

1. Identify the sample site by visual inspection and palpation, in the long head of the triceps muscle, approximately midline between the point of the elbow and the point of the shoulder.

2. Clip a zone of approximately $2 \times 2 \mathrm{~cm}^{2}$ with an electrical clipper. Apply surgical scrub consisting of polyiodide liquid soap and alcohol compresses for $1 \mathrm{~min}$ over the clipped area. Inject subcutaneously $1 \mathrm{~mL}$ of $2 \%$ lidocaine solution with a $25 \mathrm{G}$ needle in the center of the clipped and disinfected zone.

3. Scrub hands with antibacterial hand soap. Put on sterile gloves. Use a disposable sterile drape as a sterile surface to place the biopsy needle and the trocar on.

4. Arm the semi-automatic $14 \mathrm{G}$ biopsy needle by pulling the spring mechanism as shown in Figures $\mathbf{1 b}$ and $1 \mathrm{c}$. Release the biopsy needle to get familiar with its mechanism. Place the armed biopsy needle on the sterile surface. Get familiar with the trocar, which consists of a cannula and an obturator as shown in Figure 1a.

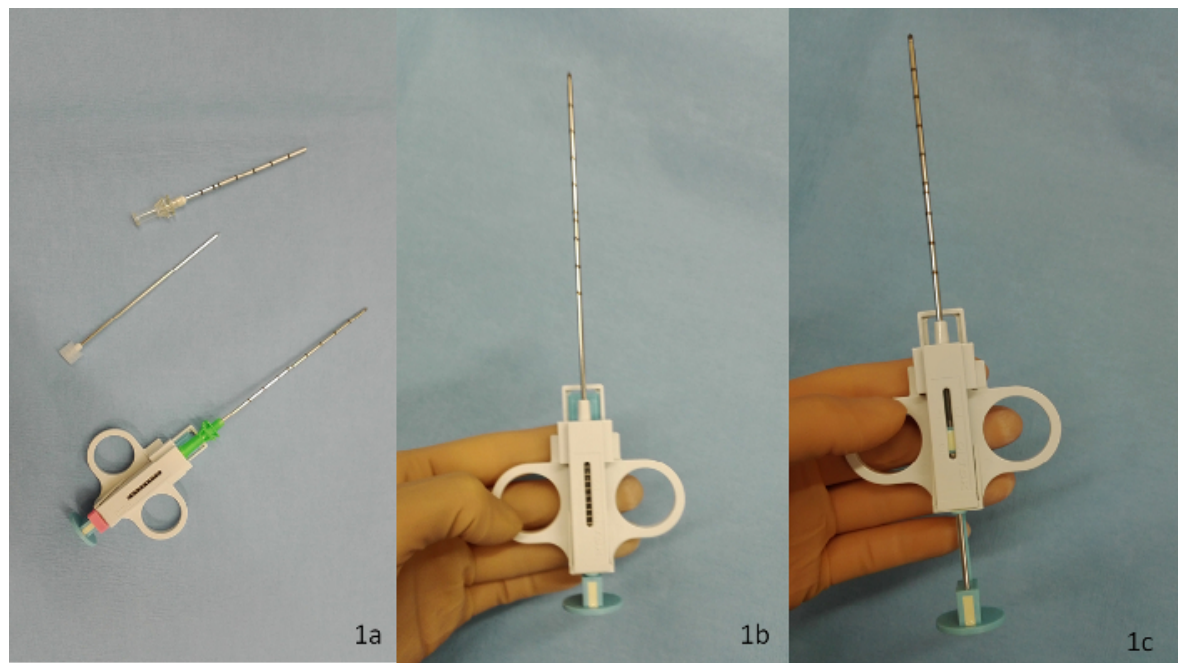

Figure 1: The biopsy needle set. The biopsy needle set consists of (a) the cannula and its obturator and the biopsy needle (from top to bottom). The other panels show the biopsy needle in its (b) neutral and (c) armed position. Please click here to view a larger version of this figure.

5. Prepare the trocar by assembling the cannula and the obturator and keep them in a locked position. Introduce the trocar perpendicularly to the skin through the formerly desensitized zone. Advance the trocar to a position where the tip of the trocar is approximately $1.5 \mathrm{~cm}$ deep in the muscle. Take the trocar out, dissociate the cannula from its obturator, and place the obturator on the sterile surface.

6. Introduce the armed biopsy needle through the cannula. Introduce the needle and the cannula through the skin incision into the muscle. Advance the needle to a position where the tip of the needle is in the middle of the long head of the triceps muscle. 
7. Release the biopsy needle and then pull out the biopsy needle together with the cannula. Pull the biopsy needle out of the cannula. Leave the cannula on the sterile surface.

8. Open the biopsy needle by pulling the spring with one hand and holding it with the other. NOTE: The specimen becomes visible at the tip of the biopsy needle.

9. With the help of a second person, open the sample tube that contains the sample medium. Use a $19 \mathrm{G}$ hypodermic needle to remove the tiny muscle piece from the biopsy needle. Place the muscle sample in the sampling medium. Close the tube with the screw cap and gently tilt it $2 x$ to ensure that the sample is floating in the medium.

10. Arm the biopsy needle. Take the cannula from the sterile surface and reassemble the armed biopsy needle and cannula. Introduce the armed needle and the cannula through the skin incision as previously described. Repeat the sample procedure 2-3x until approximately 20 mg of muscle tissue is sampled. Close the sampling tube. Gently turn the tube $2 x$ to mix the muscle pieces with the sampling medium.

11. Ship the samples to the laboratory at a constant temperature between 4 to $8^{\circ} \mathrm{C}$. NOTE: The laboratory will then process the sample. The protocol can be paused here.

12. The procedure is well tolerated and soreness at the sampling side is not observed. In the unlikely event of muscle soreness observed at the sampling site, administer appropriate analgesic treatment.

\section{Treatment of the Cells}

NOTE: The stem cells used in this study have been prepared according to the method described by Ceusters et al. ${ }^{7}$. Their article also describes the characterization of the cells.

1. Start by preparing the specific culture medium, DF20, by adding $20 \%$ of heat-inactivated fetal bovine serum, $5 \mathrm{~mL}$ of penicillin (1,000 IU/mL)streptomycin $(10,000 \mu \mathrm{g} / \mathrm{mL})$, and $2.5 \mathrm{~mL}$ of amphotericin B $(250 \mu \mathrm{g} / \mathrm{mL})$ to a bottle of $500 \mathrm{~mL}$ of a commercially available culture medium with glutamine and phenol red.

2. Pour $150 \mu \mathrm{L}$ of the DF20 culture medium into each of the inner 16 wells of a 24-multi-well dish. Pour $1 \mathrm{~mL}$ of phosphate-buffered saline (PBS) [potassium chloride $(200 \mathrm{mg} / \mathrm{L})$, potassium phosphate monophasic $(200 \mathrm{mg} / \mathrm{L})$, sodium chloride $(8,000 \mathrm{mg} / \mathrm{L})$, and potassium phosphate diphasic $(2,160 \mathrm{mg} / \mathrm{L})]$ into the remaining outer wells.

3. Rinse the tiny muscle pieces $2 x$ in PBS. Separate them into very small pieces with the help of a scalpel and forceps and place a small piece (of the size of the tip of the scalpel blade) in each inner-16 well of the multi-well dish.

4. Place the multi-well dish in an incubator maintained at the following conditions: $37{ }^{\circ} \mathrm{C}, 21 \% \mathrm{O}_{2}$, and $5 \% \mathrm{CO}_{2}$. Monitor the wells every day under an inverted microscope and add $50 \mu \mathrm{L}$ of DF20 if necessary to prevent the cells from drying out.

NOTE: After approximately $10 \mathrm{~d}$, there will be enough cells grown from the explant to allow the stem cell isolation. The protocol can be paused here.

5. When a halo of cells is visible around the muscle explants, discard the explant of muscle tissue. Detach the cells by using $150 \mu \mathrm{L}$ of an EDTA-containing trypsin solution in each well: discard the culture medium, rinse the cells with $1 \mathrm{~mL}$ of PBS, discard the PBS, and add the trypsin solution for a maximum of $10 \mathrm{~min}$ at $37^{\circ} \mathrm{C}$. Add culture medium to stop the action of the trypsin, harvest the cell suspension, and, then, centrifuge the cell suspension at $200 \times g$ for $10 \mathrm{~min}$ at $37^{\circ} \mathrm{C}$. Discard the supernatant and suspend the pellet in a balanced salt solution

6. Transfer the cell suspension on a discontinuous density gradient of 3 layers (15\%, $25 \%$, and $35 \%)$. Centrifuge the tube containing the cell suspension and the discontinuous density gradient solution at $1,250 \times g$ for $20 \mathrm{~min}$ at $25^{\circ} \mathrm{C}$. Do not use the brake of the centrifuge. Observe the cell fractions with different densities that will appear between the different layers of the discontinuous density gradient solution after the centrifugation.

7. Continue the culture with the fraction between 15 and $25 \%$. Transfer it to a tube and wash it with the balanced salt solution. Centrifuge the cell suspension at $200 \times \mathrm{g}$ for $10 \mathrm{~min}$ at $37^{\circ} \mathrm{C}$. Discard the supernatant. Proceed with suspending the pellet in $1 \mathrm{~mL}$ of DF20. Prefill a cell culture flask, with a surface of $25 \mathrm{~cm}^{2}$, with $6 \mathrm{~mL}$ of DF20. Transfer the cells into the prefilled cell culture flask and culture them in an incubator with the following conditions: $37^{\circ} \mathrm{C}, 21 \% \mathrm{O}_{2}$, and $5 \% \mathrm{CO}_{2}$. NOTE: The protocol can be paused here.

8. Monitor the cells every day under an inverted microscope. Change the culture medium if necessary (discard the old medium and add $6 \mathrm{~mL}$ of new culture medium). Determine the cellular confluence by observing the cell layers in the culture dishes, using an optical microscope at a predefined magnification. Estimate the surface of the dish that is occupied by the cells. Work at a fixed microscopic magnification for every observation to be able to evaluate the confluence. When the cells occupy $85 \%$ of the surface of the dish, proceed with a passage of the cells.

9. When the cells are confluent, detach them using an EDTA-containing trypsin solution with the same protocol as described in step 2.4. Then, centrifuge the cell suspension at $200 \times \mathrm{g}$ for $10 \mathrm{~min}$ at $37^{\circ} \mathrm{C}$. Discard the supernatant and proceed with the resuspension of the cells in 5 $\mathrm{mL}$ of DF20. Place them into a cell culture flask of $175 \mathrm{~cm}^{2}$ prefilled with $25 \mathrm{~mL}$ of DF20. Place the flask in an incubator with the following conditions: $37^{\circ} \mathrm{C}, 21 \% \mathrm{O}_{2}$, and $5 \% \mathrm{CO}_{2}$. NOTE: The protocol can be paused here.

10. Monitor the cells every day under an inverted microscope. Change the medium if necessary (discard the old medium and add $30 \mathrm{~mL}$ of new medium). When the cells are confluent, detach them using trypsin-EDTA as described in step 2.4. Then, centrifuge the cell suspension at 200 $\mathrm{x} g$ for $10 \mathrm{~min}$ at $37^{\circ} \mathrm{C}$. Discard the supernatant and suspend the cells in $6 \mathrm{~mL}$ of DF20. Place $1 \mathrm{~mL}$ of the cell suspension into six $175-\mathrm{cm}^{2}$ flasks, each prefilled with $25 \mathrm{~mL}$ of DF20, and culture them at $37^{\circ} \mathrm{C}$ in a $\mathrm{CO}_{2}$ incubator (with $21 \% \mathrm{O}_{2}$ and $5 \% \mathrm{CO}_{2}$ ).

11. Monitor the cells every day under an inverted microscope. Change the medium if necessary (discard the old medium and add $30 \mathrm{~mL}$ of new medium in each flask). When the cells are confluent, detach them using trypsin-EDTA as described in step 2.5. Centrifuge them $3 \times$ at $200 \times g$ for $10 \mathrm{~min}$ at $37^{\circ} \mathrm{C}$ and discard the supernatant at each step.

12. Count the cells with the help of a Bürker counting chamber and a light microscope. Prepare a cellular suspension of $10 \mathrm{million}$ cells $/ \mathrm{mL}$ of a specific cryopreservation medium.

13. Deep-freeze the therapeutic doses of $1 \times 10^{7}$ cells in $1 \mathrm{~mL}$ of cryopreservation medium and store them in the vapor phase of liquid nitrogen until their use.

NOTE: The protocol can be paused here.

14. Ship the cells in the vial on dry ice for final use. 


\section{Injection of the Cells}

NOTE: Two people are required to perform the injection of the stem cells.

1. Warm the cell suspension progressively to room temperature. Aspirate the suspension into a $2 \mathrm{~mL}$ syringe.

2. Sedate the horse by injecting detomidine $10 \mu \mathrm{g} / \mathrm{kg}$ into the jugular vein with a $19 \mathrm{G}$ hypodermic needle. Wait for $5 \mathrm{~min}$ to see the full effect of the sedation, which becomes visible by the characteristic head-down position of the horse.

3. Clip a zone of $20 \times 10 \mathrm{~cm}^{2}$ over the left laryngeal region of the horse with a clipper, as shown in Figure 2. Then, apply a surgical scrub of polyiodide soap and alcohol to the clipped region.

4. Place a flexible standard video endoscope through the left nostril of the horse and advance it toward the nasopharynx. Adjust the position of the endoscope until a full view of both arytenoid cartilages and the epiglottis is obtained. Hold the endoscope in this position during the procedure and turn the screen of the video endoscope toward the operators.

5. Connect the stimulation/injection needle to the nerve stimulator's negative electrode. Maintain the sterile conditions of the needle. Connect the positive electrode of the nerve stimulator to an electrode patch, which is stuck to the area of clipped skin.

6. Connect the syringe containing the cell suspension to the injection line and prefill the tube to chase the air of the system. Remember the volume of the system and prepare a syringe with the same volume of sterile saline solution.

7. If not familiar with this technique, use a disinfected 5 to $7 \mathrm{MHz}$ linear ultrasound transducer to visualize the anatomical structures in the region of interest. Use a sterile ultrasound coupling gel to increase the image quality. Visualize the larynx and the vessels that run in the dorsal region of the larynx.

8. Once familiar with the anatomy of the region, introduce the stimulation/injection needle toward the dorsolateral aspect of the larynx. When approaching the dorsolateral aspect of the larynx, start the nerve stimulator in the $1 \mathrm{~Hz}$ stimulation mode with a current of $2 \mathrm{~mA}$.

9. Gently move the needle toward the position of the recurrent laryngeal nerve while observing the endoscopic view on the screen. As soon as the abduction movement of the left arytenoid cartilage is visible on the video screen, reduce the current until the movement disappears while keeping the needle in place.

10. Identify the ideal position of the needle. Consider a loss of motor response at $0.5 \mathrm{~mA}$ as the ideal distance from the nerve. When arytenoid cartilage movements persist at currents lower than $0.4 \mathrm{~mA}$, do not inject the cells, as that may result in an intraneuronal injection.

11. When the loss of motor response at $0.5 \mathrm{~mA}$ is observed, inject the cell suspension containing $10^{7}$ autologous stem cells and flush the injection line with the saline solution prepared in step 3.6. This will inject the rest of the cell suspension that remained in the injection tube.

12. After the injection of the cells, take out the needle and the endoscope.

13. Let the horse recover from the sedation. No further treatment is needed for the biopsy site.

\section{Representative Results}

The commission for the ethical use of animals of the University of Liege approved the study protocol. Six horses from the herd of research horses at the Mont-le-Soie Equine Research Centre were included in this study. In the first horse, the recurrent laryngeal nerve was localized by electrostimulation. Figure 2 shows the setting used, with the stimulation needle inserted into the left dorsolateral aspect of the larynx of the horse in the nerve stimulator. When the loss of movement of the arytenoid cartilage is observed at $0.5 \mathrm{~mA}, 1 \mathrm{~mL}$ of $2 \%$ lidocaine is injected. This resulted in an absence of movement at higher currents and a transitory paralysis of the left arytenoid. The control endoscopy, $24 \mathrm{~h}$ later, revealed a complete recovery of the arytenoid function. The full protocol was successfully repeated in five horses. None of the horses showed a negative reaction to the muscle microbiopsy. In all horses, a sufficient number of cells were grown in the set time. The upper airway endoscopy was performed in all five horses and the laryngeal function scores of I or II.1 according to Robinson et al. ${ }^{14}$ were determined. All horses tolerated the nerve stimulation of the recurrent laryngeal nerve very well. No adverse reaction was observed during or after the stimulation or the injection of the stem cells.

All endoscopies were recorded and scored by two blinded clinicians. There was no difference between the pre-injection scores of the laryngeal functions and the scores obtained on day 1,7 , and 28 after the stem cell injection, as tested by Wilcoxon rank analysis ${ }^{15}$. Table 1 summarizes the laryngeal scores of all horses at different time points, as well as the time from the insertion of the needle to the injection of the stem cells and the current that provoked the arytenoid movement when the cells where injected.

The cells that have been used in the present study were prepared according to a protocol published previously ${ }^{7}$. The cells from all the fractions were able to trilineage differentiation, expressed CD90 and CD44, did not express CD45 and MHC II, and had clonogenic capacities. The cells of the $15-25 \%$ fraction have been chosen for further processing because they showed the greatest expression of CD90 and the biggest proliferative capacities.

The aim of the present study was not to test the efficiency of the stem cell application to regenerate a damaged peripheral nerve but only to test the feasibility of the procedure and to assess the safety of the stem cell injection to the recurrent laryngeal nerve in a small number of healthy horses. An absence of any functional changes on the endoscopic imaging in the five horses up to 28 days after the injection and an absence of any clinical signs in four of the five horses up to 1 year after the injection confirms the feasibility and the safety of the procedure. One horse had to be euthanized in the follow-up period for reasons unrelated to the study. Although the techniques prove to be safe in a small number of horses, the number of horses included in the present study is too low to demonstrate an absence of rare events. 


\begin{tabular}{|c|c|c|c|c|c|c|}
\hline & $\begin{array}{l}\text { Score before } \\
\text { injection }\end{array}$ & $\begin{array}{l}\text { Time to injection } \\
\text { (min) }\end{array}$ & \begin{tabular}{|l} 
Current at \\
injection (mA)
\end{tabular} & $\begin{array}{l}\text { Score at day } 1 \\
\text { post injection }\end{array}$ & \begin{tabular}{|l|} 
Score at day 7 \\
post injection
\end{tabular} & \begin{tabular}{|l} 
Score at day 28 \\
post injection
\end{tabular} \\
\hline $\begin{array}{l}\text { Horse } 1 \\
\text { (Standardbred, } \\
\text { mare, } 16 \text { years } \\
\text { old) }\end{array}$ & \begin{tabular}{|l|l} 
III. \\
\end{tabular} & 12 & 0.5 & 1 & \begin{tabular}{|l|l} 
II. \\
\end{tabular} & \begin{tabular}{|l|l} 
II. \\
\end{tabular} \\
\hline $\begin{array}{l}\text { Horse } 2 \\
\text { (Standardbred, } \\
\text { mare, } 22 \text { years } \\
\text { old) }\end{array}$ & 1 & 3 & $\mid 0.7$ & 1 & 1 & 1 \\
\hline $\begin{array}{l}\text { Horse } 3 \\
\text { (Standardbred, } \\
\text { mare, } 11 \text { years } \\
\text { old) }\end{array}$ & \begin{tabular}{|l|l} 
II. \\
\end{tabular} & 4 & 0.5 & |II.2 & \begin{tabular}{|l|l} 
II. \\
\end{tabular} & \begin{tabular}{|l|l} 
II. \\
\end{tabular} \\
\hline $\begin{array}{l}\text { Horse } 4 \\
\text { (Standardbred, } \\
\text { mare, } 12 \text { years } \\
\text { old) }\end{array}$ & 1 & 7 & 0.5 & 1 & \begin{tabular}{|l|l} 
II.1 \\
\end{tabular} & 1 \\
\hline $\begin{array}{l}\text { Horse } 5 \\
\text { (Standardbred, } \\
\text { mare, } 10 \text { years } \\
\text { old) }\end{array}$ & 1 & 3 & \begin{tabular}{|l|l}
0.7 \\
\end{tabular} & \begin{tabular}{|l|l}
11.1 \\
\end{tabular} & 1 & \\
\hline
\end{tabular}

Table 1: Signalment and laryngeal function scores of the horses. This table shows the time of injection, the lowest current provoking any arytenoid movement before the injection, and the laryngeal scores of five healthy horses before and at day 1,7 , and 28 after the injection of autologous muscle-derived mesenchymal stem cells in proximity to the left laryngeal recurrent nerve. Horse \#5 was not available for the control at day 28 after the injection for reasons unrelated to this study. The scores refer to the scores described by Robinson et al. ${ }^{14}$. Here, score I means that the movements of both arytenoid cartilages were synchronous and symmetrical, and a complete abduction of both arytenoid cartilages could be obtained and maintained. Score II.1 means that the movements of the arytenoid cartilages were asynchronous or may be asymmetric at certain times; however, a complete abduction of both arytenoid cartilages could be obtained and maintained.

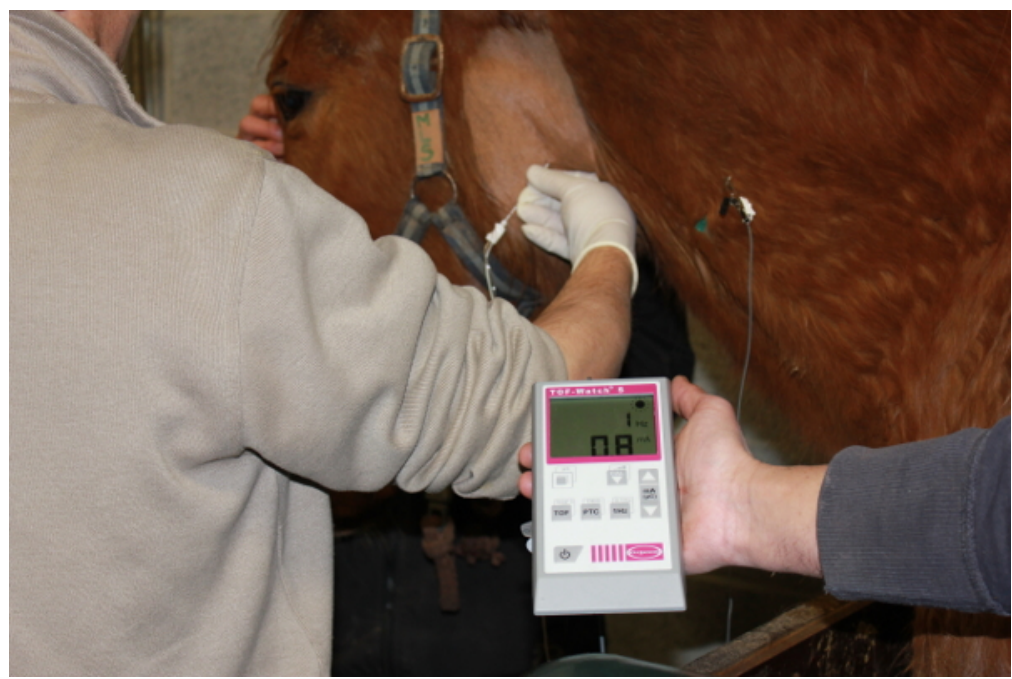

Figure 2: Setting during the injection of the stem cells. The nerve stimulation needle is introduced on the left side of the larynx and directed toward the left recurrent laryngeal nerve. The nerve stimulator is set at $0.8 \mathrm{~mA}$. Please click here to view a larger version of this figure.

\section{Discussion}

This protocol describes the successful application of muscle-derived autologous stem cells to the recurrent laryngeal nerves in horses using a nerve stimulator-guided approach. The harvest of the muscle microbiopsy specimen, as well as the isolation, culture, and characterization of the stem cells, have been described in detail before, while the injection of these cells in proximity to a peripheral nerve is original. The electrolocalization of the nerve with an electrical nerve stimulator has served for the present study and was used to inject mesenchymal stem cells in direct proximity to the recurrent laryngeal nerve. The motor response was monitored by video endoscopy through the nasopharynx. If, during the positioning process of the needle, other nerves were stimulated, the corresponding movement was visible on the endoscopy screen. A successful stimulation of the recurrent laryngeal nerve was characterized by the typical abduction of the arytenoid cartilage. In one horse, local anesthetic was injected to induce a transient paralysis of the arytenoid muscle. Although the successful implantation of the cells in proximity to the nerve has not been tested specifically in the present study, the electro-localization of the nerve and the injection at a low current proved that 
the stem cells were applied near the nerve. The proximity of the injectate to the nerve was further demonstrated by a successful motor block induced by an injection of a local anesthetic.

In the remaining five horses, the time from the first stimulation until the successful stem cell injection varied from 3 to 12 min. Horses were slightly sedated during the procedure, which increased their compliance with the electrical stimulation. None of the horses showed adverse reactions at any time, indicating that the duration of the stimulation can be prolonged if necessary to obtain good needle positioning. A steep learning curve is expected to be observed if the operator is using this technique regularly and in a larger number of horses with varying anatomy.

Horses commonly suffer from RLN, which is characterized by varying degrees of paralysis of the left arytenoid cartilage leading to abnormal respiratory sounds and exercise intolerance. A histology of affected nerves reveals typical lesions of peripheral neuropathy ${ }^{16}$. Peripheral neuropathy is a term used to describe various types of peripheral nerve lesions leading to impaired sensations, movements, or organ functions. The causes are highly variable and may include diabetes, nutrient deficiencies, a treatment with specific drugs, a traumatic injury, ischemia, or an infection, or they can be idiopathic. Independent of the cause, peripheral neuropathies share common histopathological signs, such as Wallerian degeneration, distal axonopathy, or segmental demyelination. It has been shown that the administration of mesenchymal stem cells to damaged peripheral nerves may be beneficial for their regeneration; however, the underlying mechanisms are not well understood. Traditionally, we believe that mesenchymal stem cells will only differentiate into progenitors of adipose, muscle, cartilage, and bone tissue, but under specific conditions, they have been shown to differentiate into myocytes ${ }^{17}$, astrocytes ${ }^{18}$, and myelinating cells of the peripheral ${ }^{19}$ and central nervous system $^{19}$. During an in vitro culture, an exposure to neuropeptides will favor the differentiation of mesenchymal stem cells into cells expressing neuronal markers ${ }^{21,22}$. Several in vivo studies have demonstrated the beneficial effect of mesenchymal stem cells on nerve regeneration and a functional recovery in rat models of sciatic nerve injury ${ }^{10,23}$. This is probably caused by favorable environmental conditions that contribute to the differentiation of stem cells into tissue-specific cells ${ }^{24}$. Future studies should also investigate this technique for the administration of predifferentiated cells in RLN-affected horses.

To the best of our knowledge, this is the first report that describes the use of a nerve stimulator to localize a peripheral nerve in order to inject a specific treatment into it. Other peripheral nerve pathologies in various species, such as neuropathic pain, can be treated by the administration of stem cells in proximity to the nerve ${ }^{25,26}$. Future studies should test the effect of this technique in clinical patients and investigate the risk of migration and the potential of differentiation of the injected cells.

\section{Disclosures}

The authors have nothing to disclose.

\section{Acknowledgements}

The study has been funded by the Mont-le-Soie Equine Research Centre.

\section{References}

1. Duncan, I.D., Griffiths, I.R., Madrid, R.E. A light and electron microscopic study of the neuropathy of equine idiopathic laryngeal hemiplegia. Neuropathology and Applied Neurobiology. 4 (6), 483-501 (1978).

2. Cahill, J.I., Goulden, B.E. Equine laryngeal hemiplegia. IV. Muscle pathology. New Zealand Veterinary Journal. 34 (11), 186-190 (1986).

3. Dixon, P.M. et al. Laryngeal paralysis: a study of 375 cases in a mixed-breed population of horses. Equine Veterinary Journal. 33 (5), $452-458$ (2001).

4. Hahn, C. Review of the pathological changes in equine recurrent laryngeal neuropathy. In: Havemeyer Workshop on Equine Laryngeal Neuropathy. Havemeyer Monograph Series No. 11. Edited by Dixon, P.M., Robinson, E., Wade, J.F., 9-11, R\&W Publications. Newmarket, UK (2003).

5. Biasutti, S., Dart, A.J., Jeffcott, L.B. A review of recent developments in the clinical application of prosthetic laryngoplasty for recurrent laryngeal neuropathy: Indications, complications and outcome. Equine Veterinary Education. 29 (6), 337-345 (2016).

6. Barnett, T.P., O'Leary, J.M., Parkin, T.D.H., Dixon, P.M., Barakzai, S.Z. Long-Term Maintenance of Arytenoid Cartilage Abduction and Stability During Exercise After Laryngoplasty in 33 Horses. Veterinary Surgery. 42 (3), 291-295 (2013).

7. Ceusters, J. et al. From skeletal muscle to stem cells: an innovative and minimally-invasive process for multiple species. Scientific Reports. 7 (1), 696 (2017)

8. Ding, D.C., Shyu, W.C., Lin, C.Z. Mesenchymal Stem Cells. Cell Transplantation. 20 (1), 5-14 (2011).

9. Jiang, L., Jones, S., Jia, X., Stem Cell Transplantation for Peripheral Nerve Regeneration: Current Options and Opportunities. International Journal of Molecular Sciences. 18 (1), 94 (2017).

10. Tohill, M., Mantovani, C., Wiberg, M., Terenghi, G. Rat bone marrow mesenchymal stem cells express glial markers and stimulate nerve regeneration. Neuroscience Letters. 362 (3), 200-203 (2004)

11. Ji, J.F., He, B.P., Dheen, S.T., Tay, S.S.W. Interactions of Chemokines and Chemokine Receptors Mediate the Migration of Mesenchymal Stem Cells to the Impaired Site in the Brain After Hypoglossal Nerve Injury. Stem Cells. 22 (3), 415-427 (2004).

12. Urmey, W.F. Using the nerve stimulator for peripheral or plexus nerve blocks. Minerva Anesthesiologica. 72 (6), $467-471$ (2006).

13. De Andrés, J., Sala-Blanch, X. Peripheral nerve stimulation in the practice of brachial plexus anesthesia: a review. Regional Anesthesia and Pain Medicine. 26 (5), 478-834 (2001).

14. Robinson, N.E. Consensus statements on equine recurrent laryngeal neuropathy: conclusions of the Havemeyer Workshop. Equine Veterinary Education. 16 (6), 333-336 (2004)

15. The BMJ: Rank Score Tests. https://www.bmj.com/about-bmj/resources-readers/publications/statistics-square-one/10-rank-score-tests. June 12, 2018. (2018) 
16. Hahn, C.N., et al. Histological and ultrastructural evidence that recurrent laryngeal neuropathy is a bilateral mononeuropathy limited to recurrent laryngeal nerves. Equine Veterinary Journal. 40 (7), 666-672 (2008).

17. Orlic, D. et al. Bone marrow cells regenerate infarcted myocardium. Nature. 410 (6829), 701-705 (2001).

18. Kopen, G.C, Prockop, D.J., Phinney, D.G. Marrow stromal cells migrate throughout forebrain and cerebellum, and they differentiate into astrocytes after injection into neonatal mouse brains. Proceedings of the National Academy of Science. 96 (19), 10711-10716 (1999).

19. Dezawa, M., Takahashi, I., Esaki, M., Takano, M., Sawada, H. Sciatic nerve regeneration in rats induced by transplantation of in vitro. differentiated bone marrow stromal cells. European Journal of Neuroscience. 14 (11), 1771-1776 (2001).

20. Akiyama, Y, Radtke, C, Honmou, O., Kocsis, J.D. Remyelination of the spinal cord following intravenous delivery of bone marrow cells. Glia. 39 (3), 229-236 (2002).

21. Mahanthappa, N.K., Anton, E.S., Matthew, W.D. Glial growth factor 2, a soluble neuregulin, directly increases Schwann cell motility and indirectly promotes neurite outgrowth. Journal of Neuroscience. 16 (15), 4673-4683 (1996).

22. Sanchez-Ramos, J. et al. Adult bone marrow stromal cells differentiate into neural cells in vitro. Experimental Neurology. 164 (2), $247-256$ (2000).

23. Farzamfar, S., et al. Sciatic nerve regeneration by transplantation of menstrual blood-derived stem cells. Molecular Biology Reports. 44 (5), 407-412 (2017).

24. Morrison, S.J., Shah, N.M., Anderson, D.J. Regulatory mechanisms in stem cell biology, Cell. 88 (3), $287-298$ (1997).

25. Brini, A.T. et al. Therapeutic effect of human adipose-derived stem cells and their secretome in experimental diabetic pain. Scientific Reports. 7 (1), 9904 (2017).

26. Liu, W. et al. Autologous Bone Marrow-Derived Stem Cells for Treating Diabetic Neuropathy in Metabolic Syndrome. Biomed Research International. 2017, 8945310 (2017). 